\title{
Determination Of Total Petroleum Hydrocarbons (TPHs) In Weathered Oil Contaminated Soil
}

\author{
meshari Almutairi ${ }^{1}$ \\ ${ }^{1}$ Affiliation not available
}

June 22, 2020

\begin{abstract}
A new measurement method of weathered crude oil in soil was reviewed. There is no standard method for the extraction of crude oil from soil. Therefore, a basic initial test was carried out and several methods such as gravimetric and gas chromatographymass spectrometry (GC-MS) with various parameters such as weight, solvent and time were altered to improve the measurement process. The gravimetric process was demonstrated to be the most effective for quantifying weathered contamination crude oil in contaminated soil. The dichloromethane DCM, mixture of DCM: hexane (1:1 v/v mix) and mixture of acetone: hexane (1:1 $\mathrm{v} / \mathrm{v}$ mix) was used to investigate the ability of solvent extraction technique for removing weathered crude oil from soil under various extraction conditions. The mixtures of acetone: hexane $(1: 1 \mathrm{v} / \mathrm{v}$ mix $)$ were demonstrated to be the most effective in removing total petroleum hydrocarbons $(\mathrm{TPH})$ from contaminated soils on average of $341,000 \mathrm{mg} / \mathrm{kg}$. $5 \mathrm{~g}$ and $1 \mathrm{~g}$ weights of the oil-contaminated samples were studied to select the best weight depending on contamination level. The out comes shown that the $1 \mathrm{~g}$ of contaminated soil was cleaned in three cycles whilst the $5 \mathrm{~g}$ of contaminated soil required six cycles. This paper indicated that the selected parameters were able to recover about $97.20 \%$ of the weathered crude oil. Also, these parameters were influenced with character of high efficiency, low cost, low toxicity and short time.
\end{abstract}

\subsection{Introduction}

Upon the release of oil into the environment, a broad spectrum of chemical, physical and biological processes occurs during the transformation of the released oil. These processes are collectively known as weathering, which describes the action of altering the composition, performance, exposure and the level of toxicity of the oil [1]. According to the United State Environmental Protection Agency (USEPA), have identified that petroleum contaminated soil can be detrimental to the health of people and animals, affecting the liver, lungs, kidney and nervous system, causing cancer, disorder of immune and reproductive system [2].

There are several methods to determine the total oil content such as total organic carbon (TOC), total carbon (TC), total petroleum hydrocarbon (TPH) etc. Based on environmental sciences division UK [3], TPH is commonly used gross parameter for quantifying environmental contamination originated by petroleum hydrocarbons compounds (PHC) products such as fuels, oils, lubricants, waxes and others. TPH can be classified into four main structural forms: aliphatic, aromatic, resins and asphaltenes compounds. Aromatic hydrocarbons are characterised into two groups based on their molecular structure. These are low molecular weight (LMW) compounds and high molecular weight (HMW) compounds [4]. Traditional wet chemistry methods for determining TPH level is based on extracting the contaminant from the soil sample. The TPH level in the extracted solution is can be determined by several methods such as gravimetric or gas chromatography-mass spectrometry (GC-MS) measurement calibrated by an EPA calibration standard. A series of experimental tests were conducted by Rababah and Matsuzawa [5], Khodadoust et al. [6]; Silva et al. [7], Li et al. [8], at laboratory environment for a range of solvents with various ratios and different time to enhance the extraction process. 
According to Li et al. [8], number of experiments were performed at the solvent soil ratio of 2:1, 3:1, 6:1 to assess the extraction efficacy. They found that the solvent extraction with greater than $95 \%$ removal at $3: 1$ solvent soil ratio was suitable in removing oil contaminants. Another experimental test was conducted by Khodadoust et al. [6] for a range of solvents including combinations of solvents to determine hydrocarbons from extremely polluted soil. The experiment revealed that washing procedure of 60 min has successfully eliminated $95 \%$ of extractable hydrocarbons compounds. With the exception of type of solvent, the extraction performance is also reliant upon the ratio of soil; solvent. For example, a study was carried by Silva et al. [7] by means of magnetic agitation on the effectiveness of a mix comprising $40 \%$ acetone $+50 \%$ ethyl acetate $+10 \%$ water to get rid of naphthalene from soil samples at various soil: solvent ratios of 1:1, 1:2, 1:3, 1:4 and 1:8 (w/v). It was revealed that a ratio of 1:8 was required to achieve the most efficient removal process. However, Rababah and Matsuzawa [5] discovered that the most efficient solvent was cyclohexane and ethanol mixture at a ratio of 3:1, with excellent removal efficiency of around $93 \%$ as well as from the safety aspect.

Due to the lack of information regarding the concentration of petroleum hydrocarbons in the Kuwait oil sand, this study was designed to measure the total petroleum hydrocarbon concentration (TPH), due to its ability to determine a broad family of several hundreds of chemical compounds present in crude oil. The most important reason for selection of TPH over other methods is that the core contaminants to be analysed are petroleum based which would delineate the level of oil pollution while the other methods are less relevant in this case. Another reason for the choice of TPH is that it gives a direct indication of the degree of pollution resulting from oil which is required by regulatory agencies.

\subsection{Materials and methods}

\subsection{Preparation of Oil contaminated Sand}

The sample of oil contaminated sand was obtained from Kuwaiti oil lake. In order to enhance the efficiency of measurement efficacy, the process requires the soil to be homogeneous before the washing. $1 \mathrm{~kg}$ of sample was screened manually through $13.5 \mathrm{~mm}$ sieve for $2 \mathrm{~min}$, to segregate materials finer than gravel coarse aggregate and to separate out the larger clumps of congealed oil residue.

\subsection{Extraction process}

Contaminated soil (1g) was mixed with Hydromatrix concentrate (Varian, UK) at a ratio of 1:1 w/w. The mix was then ground vigorously to such an extent that it appeared dry and powdery. The sample was then added to $22 \mathrm{ml}$ stainless steel extraction vial (Dionex, UK) partitioned with disposable cellulose filters (Dionex, 52 UK) and acid washed sand (VWR, UK). Accelerated solvent extractor (ASE) 200 (Dionex, UK) was utilised to perform the extraction process by using Dionex method 324. To facilitate the extraction process, the ASE cell is left in an ASE carousel. Whilst extraction takes place, hexane/acetone, 1:1 (Fisher Scientific, UK) was introduced into the extraction cell up to $50 \mathrm{ml}$. Upon extraction, the extract was flushed out of the cell into a collection vial with the help of nitrogen, to be analysed. GC-MS was utilised to perform the analysis on the extract. Then, $1.5 \mathrm{ml}$ of the specimen solution was pipetted into the GC auto sampler vial (Technopath, UK) and capped by crimp caps.

\subsection{Measuring the levels of weathered crude oil by GC-MS}

The GC-MS has been widely used in recent environmental research due to its effectiveness with regards to many major classes of organic samples. Analyses of weathered crude oil in terms of TPH were performed on a Varian 43GC and a Varian 21-MS IT with an auto-sampler CP-8400 (Figure 3-1) in order to examine and assess traces of petroleum hydrocarbons in the soil sample. A DB-5 MS capillary column (15 m x 0.32 $\mathrm{mm}$ i.d. $\mathrm{x} 0.1 \mu \mathrm{m}$ film) was used for the GC-MS. A GC-MS works by mixing the specimen solution with helium and air in the column. The GC- MS had the following conditions: injector temperature, $300{ }^{\circ} \mathrm{C}$; oven temperature program, $50{ }^{\circ} \mathrm{C}$ for $2 \min -300^{\circ} \mathrm{C}$ for $20 \min$ at $5{ }^{\circ} \mathrm{C} / \mathrm{min} .1 \mu \mathrm{l}$ sample of the sample was introduced into the GC inlet by injection in which it vapourised and swept onto a chromatography column by helium which is used as the carrier with a constant flow rate of $1.0 \mathrm{ml} / \mathrm{min}$ at $300^{\circ} \mathrm{C}$ and then carried on to the MS console. Electron impact mode was used for ionisation of the sample. The MS was scanned from 
$m / z 35-550$, with 3 min solvent delay and a 150-threshold count.

2.4 Gravimetric method for analysis of weathered crude oil

Gravimetric method is based on two phases, the first phase aimed to extract the weathered crude oil from sand while the second phase aimed to determine the percentage of total petroleum hydrocarbons recovered from contaminated sand. The oil was extracted from the sand based on the following procedure. One gram of contaminated sample was placed into a screw-capped bottle with $5 \mathrm{ml}$ of acetone: hexane solvent $(1: 1 \mathrm{v} / \mathrm{v})$ and washed for 5 minutes in ultrasonication bath. The solution of crude oil and mixture of acetone: hexane was pipetted into a clean and dry weighed round-bottomed glass flask. The ultrasonication cycle was then repeated for four times using fresh solvent in each cycle.

The isolated sand was left to air dry for 2 hours and then noted the dry weight. The collection apparatus, conical flask, distillation head with condenser side arm and water bath were prepared and fixed to determine the percentage of total recoverable petroleum hydrocarbons. The water bath temperature was maintained at $52^{\circ} \mathrm{C}$, to accelerate the evaporation of the acetone: hexane mix. Finally, when the acetone: hexane mix was recovered, the round glass flask was dried, then the total weight of crude oil in the soil sample was re-weighed to calculate the concentration of isolated weathered crude oil.

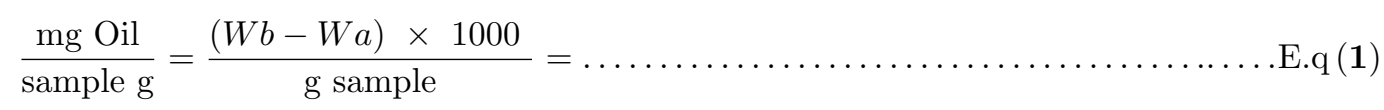

Where, the weight of the crude oil sediment plus the round flask is $\mathrm{Wb}$, while the weight of the round flask is Wa. While, the percentage removal of weathered crude oil is calculated by

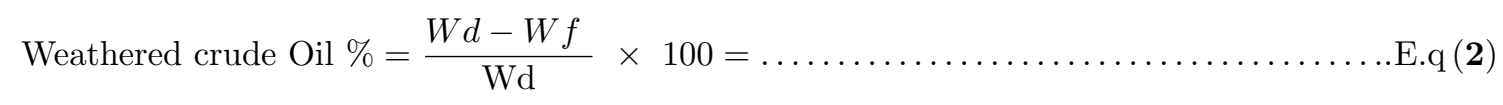

Where, the initial concentration of the weathered oil in the soil (g) before washing is Wd, while the concentration of weathered crude oil in the soil (g) after washing is Wf.

\subsection{Results and discussion}

\subsection{Analysis of weathered Oil Using Gas Chromatography-Mass Spectrometry (GC-MS)}

Any extraction procedure used in analytical chemistry is primarily intended to detach the analyte from its matrix quantitatively, speedily and utilising as little solvent as possible [9]. A procedure known as accelerated solvent extraction (ASE) has been employed for the quantitative extraction of a number of semi-volatiles comprising Polycyclic Aromatic Hydrocarbons (PAHs), phenols, polychlorinated biphenyls (PCBs) as well as total petroleum hydrocarbons $[8 ; 10]$.

An instrumental method known as GC-MS consisting of a gas chromatograph (GC) coupled to a mass spectrometer (MS) in an effort to separate, identify and quantify complex mixture of chemicals. This proves to be the most appropriate method to analyse hundreds of compounds with comparatively LMW. The compound itself has to be thermally stable and satisfactorily volatile so that it can be analysed using GCMS technique. However, this study was conducted using GS-MS to analysed weathered oil in soil. Preliminary study was conducted for the Kuwait oil sand, the initial results from the GC-MS analyses indicated that the concentrations of TPH varied from 183,432 to $212,993 \mathrm{mg} / \mathrm{kg}$. No traces of PAH compounds were found in the sample by this analysis. The GC profile for TPH showed that after 15 minutes the TPH level started to increase, indicating that the sample contains long chain hydrocarbon compounds, Figure (1).

Figure 1: Here

Before carrying out GC analysis, chemical modification of the sample is essential to eliminate interfering compounds that may affect the quality of the data obtained. Hence, a high content of asphaltenes was removed to get a correct reading for aliphatic and, aromatic compounds and to protect the GC. However, 
the main portion of the diesel oil is not characterized as most of the constituents cannot be resolved. In the chromatogram, these constituents look like a 'hump', which is termed unresolved complex mixture' (UCM), containing branched, cyclicalkanes and polar transformation products [11]. The resolved hydrocarbons are named 'total resolved hydrocarbons (TRH). The TRH and UCM combine to become TPH. In the GC-MS, the TRH are shown as peaks, which are non-degraded hydrocarbons, as shown in Figure (2).

Figure 2: Here

However, this method faced some challenges during the measurement, one of the main difficulties caused by GC column which was blocked after each run. This necessitated the development of another alternative method for the analysis of TPH from soil samples, as given in the next section.

\section{Analysis of Weathered Crude Oil Using Gravimetric Method}

Currently, there is no standard method for determination of TPH in contaminated soil with petroleum hydrocarbon products [12]. A number of researchers [13; 14] have developed and utilised various methods for this purpose. Most of the techniques for separating oil from the sand in the laboratory involves ASE, soxhlet extraction or ultrasonication. Ultrasonication with aid of an appropriate solvent has been selected to extract oil from the sand, since it is easily available with high extraction efficiency and economical. The amount of weathered crude oil can then be calculated by gravimetric technique.

Different sample weight

starting with the most polluted sample, the $5 \mathrm{~g}$ and $1 \mathrm{~g}$ weights of the oil-contaminated samples were selected depending on contamination level. The $1 \mathrm{~g}$ of contaminated soil was cleaned in three cycles whilst the $5 \mathrm{~g}$ of contaminated soil required six cycles. After the washing process is completed, the weight of the oilcontaminated soil sample after extraction and the weight of the crude oil were calculated using the equation 1 , data is presented in Table (1).

Table 1: Here

One-gram sample was cleaned in $30 \mathrm{~min}$ with $15 \mathrm{ml}$ of solvent, in comparison with the $5 \mathrm{~g}$ sample, which needs $60 \mathrm{~min}$ with $150 \mathrm{ml}$ of solvent to complete cleaning. However, the interaction between the extraction solvent and oil contaminants was unlikely to be changed by increasing the weight of the soil sample. Therefore, $1 \mathrm{~g}$ was recommended in this study.

Type of solvent

This technique involved determining the suitable solvents for the extraction of crude oil from sand in a short period with high extraction efficiency and a less harmful product. There is a wide range of solvents which can be used, such as hexane, dichloromethane (DCM) and chloroform. The selected solvents for this experiment are DCM, DCM: hexane (1:1 mix) and acetone: hexane (1:1mix), these solvents were found to be the most effective solvent compared to other solvents in isolation of organic compounds from soil [8; 15]. The selected solvents were tested using the same procedures carried out in three trials by applying the basic method described in Section 2.4. The ultrasonication process cleaned $1 \mathrm{~g}$ of contaminated soil, in three washes all with different solvents trialed. After the completion of the solvent recovery process, the weight of sand for all three samples and recovered oil were calculated, as exhibited in Table (2).

Table 2: Here

Based on Table (2), the highest crude oil concentration on average was $341,000 \mathrm{mg} / \mathrm{kg}$ for the solvent combination of acetone: hexane $(1: 1 \mathrm{v} / \mathrm{v})$. Chloroform is not recommended in this study since it affects the central nervous system, such that people who are exposed to chloroform with a certain amount can become unconscious. The mixture of acetone: hexane has a high extraction efficiency due to its dependency on the solvent mixture polarity for eliminating oil contaminants. Moreover, different authors have used them in the 
extraction of petroleum products from soil $[16 ; 17 ; 18 ; 19]$. This experiment has shown that the best solvent system of choice for the extraction of oil from sand was mixture of acetone: hexane $(1: 1 \mathrm{v} / \mathrm{v})$.

Different ultrasonication cycles

The main aim of trying a different ultrasonication cycle is to investigate whether a reduction of cycle improved the extraction process. The previous experiments (Section 3.2.2) required $5 \mathrm{ml}$ of acetone: hexane $(1: 1 \mathrm{v} / \mathrm{v})$ for 10 minutes per cycle for three cycles and these results were then compared with an alternative experiment, which used $5 \mathrm{ml}$ of acetone: hexane $(1: 1 \mathrm{v} / \mathrm{v})$ solvent mixture to clean $1 \mathrm{~g}$ of soil sample for four cycles with a shorter cycle time of 5 minutes for each cycle. This test demonstrates that the four cycles were required if the sample washed for 5 minutes per cycle, therefore a total volume of $20 \mathrm{ml}$ of solvent was required to complete the extraction process. However, samples washed within 10 minutes per cycle required three cycles, therefore, $30 \mathrm{ml}$ of of solvent was required for the whole process and the outcomes are presented in Figure (3).

Figure 3: Here

Based on Figure (3), there are no-significant differences in concentration of weathered crude oil was observed irrespective of the washing cycle time. The outcome showed that the mean values for 5 and 10 minutes were 344,000 and 331,000, respectively (Post-hoc Scheffe test, $P<0.05$ ). The previous experiment (Section 3.2 .2 ) required three cycles, $15 \mathrm{ml}$ of solvent and 10 minutes per cycle to wash two samples in one hour. The alternative experiment used more solvent with less time, so that three samples could be washed in one hour. Therefore, this outcome suggested the choice of 5 minute cycle over the 10 minute cycle.

Validation of gravimetric method

One-gram of clean sand was mixed with $5 \mathrm{ml}$ of fresh crude oil. The crude oil was obtained from Kuwait Oil Company (KOC). The mixture of sand and crude oil were washed in 20 minutes with $20 \mathrm{ml}$ of solvents in four wash cycles (Section 2.4). After the completion of the solvent recovery process, the weight of sand and recovered oil were calculated, as exhibited in Table (3).

Table 3:

The outcome of Table (3) indicated that the previous experiment (Section 2.4) was able to recover about $97.20 \%$ of the crude oil. This study suggested that the selection process in recovery of the crude oil is influenced by four principal characteristics: (1) minimise the cost of the extraction solvent by reducing the quantity of solvent (2) the solvent must dissolve the crude oil in the shortest time (3) high extraction efficiency and (4) select the solvent that has the least side effect. In this study, the temperature of the extraction was not examined since the volatility of the selected solvents was already high.

\subsection{Conclusion}

This study faced some challenges during the measurement, one of the main difficulties caused by GC column which was blocked after each run. Therefore, another alternative method for the analysis of TPH in contaminated soil was required to be developed. The mixtures of (acetone: hexane v/v) in mixed solvent were effective in extracting weathered oil from contaminated soils. This experiment has shown that the interaction between the extraction solvent and oil contaminants was unlikely to be changed by increasing the weight of the soil sample or the contact time. The developed gravimetrical method used more solvent with less time, so that three samples could be extracted in one hour.

\section{Acknowledgements}

The authors gratefully acknowledge the support from Sheikh Nasser Al Sabah for his motivation to get back on the wagon and continue with my research and invention. Special thanks are also to the staff of the Kuwait Oil Company (Surface Team) which helped the successful accomplishment of this research.

\section{References}


[1] Lehr, W.J. 2010. Review of modeling procedures for oil spill weathering behavior. Adv. Ecol. Sci. 9: 51-90

[2] U.S. Environmental Protection Agency (USEPA). (2009). Provisional Peer-Reviewed Toxicity Values for Complex Mixtures of Aliphatic and Aromatic Hydrocarbons. PA/690/R-09/059F Final 9-30-2009.

[3] Environmental Sciences Division (ESD). (1993). Use of Gross Parameters for Assessment of Hydrocarbon Contamination of Soils in Alberta, Oxford, UK.

[4] Khan MAI, Biswas B, Naidu ESR, Megharaj, M. (2018). Toxicity assessment of fresh and weathered petroleum hydrocarbons in contaminated soil-a review. Chemosphere 212:755-767.

[5] Rababah, A and Matsuzawa, S. (2002). Treatment system for solid matrix contaminated with fluoranthene. I-Modified extraction technique, Chemosphere 46 (1) 39-47.

[6] Khodadoust, A.P., Bagchi, R., Suidan, M.T., Brenner R.C and Sellers, N.G. (2000). Removal of PAHs from highly contaminated soils found at prior manufactured gas operations, J. Hazard. Mater. B80-159-174.

[7] Silva, A. Delerue-Matos, C and Fiuza, A. (2005)., Use of solvent extraction to remediate soils contaminated with hydrocarbons, J. Hazard. Mater. B124 - 224-229.

[8] Li, X., Du, Y., Wu, G., Li, Z; Li, H. \& Sui, H. (2012). Solvent extraction for heavy crude oil removal from contaminated soils. Journal of Chemosphere. 88 (2), 245- 249.

[9] Nollet, L.M.L. and Rathore, H.S. (2010). Handbook of pesticides: methods of pesticide residues analysis, NW/USA: Taylor \& Francis, CRC press.

[10] Mantovani C.C. Lima M.B. Oliveira, C.D. Menck, R.A. Diniz, E.M and Yonamine, M. (2014). Development and practical application of accelerated solvent extraction for the isolation of cocaine/crack biomarkers in meconium samples. Journal of Chromatography. B, Analytical Technologies in the Biomedical and Life Sciences, 957, 14-23.

[11] John W. F and James G. Q. "Unresolved Complex Mixture" (UCM): A brief history of the term and moving beyond it. Marine Pollution Bulletin 2015, 96 (1-2), 29-31

[12] U.S. Environmental Protection Agency (USEPA). (1999). Toxicological profile for Total Petroleum Hydrocarbons (TPH). Prepared by Research Triangle Institute for the U.S. Department Of Health And Human Services Public Health Service.

[13] Villalobos, M. Avila-Forcada, A. P. and Gutierrez-Ruiz, M. E. (2008). An improved gravimetric method to determine total petroleum hydrocarbons in contaminated soils. Journal of Water, Air, and Soil Pollution, vol. 194, no. 1-4, pp. 151-161.

[14] Guy, S. Eyal, B. and Gil, E. (2012). Quantitative Analysis of Total Petroleum Hydrocarbons in Soils: Comparison between Reflectance Spectroscopy and Solvent Extraction by 3 Certified Laboratories. Journal of Applied and Environmental Soil Science. Vol-751-956-11.

[15] Osman, R. and Saim, N. (2013). Selective Extraction of Organic Contaminants from Soil Using Pressurised Liquid Extraction. Journal of Chemistry. Article ID 357252, 8 pages.

[16] Somasundaran, P., Zhang, L., Zheng, J., Ososkov, V. and Chou, C. C. (1997). Removal of nonvolatile hydrophobic compounds from soils by flotation I. Laboratory investigation using a mechanically agitated machine. Journal of Advances in Environmental Research. 1 (2), 157-165.

[17] Zhang, L., Somasundaran, P., Ososkov, V. and Chou, C. C. (2001). Flotation of hydrophobic contaminants from soil. Journal of Colloids And Surfaces A-Physicochemical And Engineering Aspects. 77, 235-246.

[18] Kuk, M.S., Tetlow, R. \& Dowd, M.K. (2005). Cottonseed extraction with mixtures of acetone and hexane. Journal of the American Oil Chemists' Society. 82, 609-612. 
[19] Alena, R. Lidmila, B, Marie K. Oscar I.H.L., Lucie, Č, Pavel, L, Andrea, Ž. Karel, F. (2016). Separation of azeotropic mixture acetone + hexane by using polydimethylsiloxane membrane. Separation and Purification Technology. 170, 256-263.

\section{Hosted file}

Figure.docx available at https://authorea.com/users/335848/articles/461633-determination-oftotal-petroleum-hydrocarbons-tphs-in-weathered-oil-contaminated-soil

\section{Hosted file}

Table.docx available at https://authorea.com/users/335848/articles/461633-determination-oftotal-petroleum-hydrocarbons-tphs-in-weathered-oil-contaminated-soil 